\title{
Optimizing the Production from a Multizone Well by Selecting Appropriate Completion for a Well of Tal Block, Pakistan
}

\author{
Muhammad Rafique Arisar \\ Institute of Petroleum and Natural Gas Engineering \\ Mehran University of Engineering and Technology \\ Jamshoro, Pakistan \\ rafique.arisar@gmail.com
}

Faisla Najam Abro

Institute of Petroleum and Natural Gas Engineering Mehran University of Engineering and Technology

Jamshoro, Pakistan

faisal.abro@hotmail.com

\author{
Muhammad Zubair Hingoro \\ Institute of Petroleum and Natural Gas Engineering \\ Mehran University of Engineering and Technology \\ Jamshoro, Pakistan \\ 13pet04@student.muet.edu.pk
}

\section{Sohail Nawab}

Institute of Petroleum and Natural Gas Engineering Mehran University of Engineering and Technology Jamshoro, Pakistan. sohail.nawab@faculty.muet.edu.pk

Imran Hullio

Institute of Petroleum and Natural Gas Engineering

Mehran University of Engineering and Technology

Jamshoro, Pakistan

imran.hullio@faculty.muet.edu.pk

\begin{abstract}
Well completion is the process of construction a well geared up for production or injection. This mainly involves preparing the bottom of the hole to the required conditions and running the production tubing and associated downhole tools. Production from a multizone well can be obtained from a single tubing string as well as from dual tubing strings but it depends on pressure difference, depth and fluid present in the formation. This paper is based on the optimum well completions design for a multizone well of the Tal block region which contains four reservoirs of different formations: Lockhart (limestone), Hangu and Lumshiwal (sandstone), Samanasuk (limestone) \& Datta (sandstone) having pressures of 7432psia, $7563 \mathrm{psia}, 7843 \mathrm{psia}$, and 7982 psia respectively. The well is producing four zones (multilayer well) and the generated numerical model for each completion (single string multizone completion and dual string multizone completion) shows better performance and economic feasibility.
\end{abstract}

Keywords-completion; multilayer; permeability; single string; dual string; flowrate; drawdown

\section{INTRODUCTION}

Tal Block is an oil and gas field, located in Kohat District, Pakistan. The field accounts for $20 \%$ of Pakistan's oil production, amounting to 17,000 barrels per day [1]. Six discoveries have been made in this block, the first in 2002 and the most recent in 2011. There is a 55\% success ratio of discovery in Tal Block, compared to $33 \%$ in other areas [2]. In Tal block region, four reservoirs can be produced from one well due to low pressure, depth differences between the layers, and similar properties of the fluid present in the formations. Formations are Lockhart (limestone), Hangu and Lumshiwal (sandstone), Samanasuk (limestone), and Datta (sandstone). The purpose of well completion is to connect the reservoir to the surface so that fluid can be produced or injected securely. The best completion design must reduce the fluid losses due to friction and produce fluid efficiently. The initial study related to this topic comprises a discussion of a well completion design methodology to overcome reservoir challenges [3]. Advanced well completion solutions were used to satisfy specific reservoir and production requisites. "Intelligent well completion" contains inflow control devices and permanent downhole gauges [4]. Hydraulic fracture design and performance optimization were used for tight oil reservoirs to improve the permeability of the reservoir and the designed well completion improved the performance in case of hydraulic fracture [5]. The general idea of the design method utilizes a tubular design, supported by software, which offered an analytical method for reviewing tubing loads, design reliability and buckling behavior under composite mechanical, fluid pressure and thermal loading condition [6]. In [7], it was concluded that single trip multizone completion utilized only one trip for gravel pack or frac pack operation in a multizone

Corresponding author: Muhammad Rafique Arisar 
well. The production from a multizone well can be either taken from single tubing string or dual tubing string, depending on the conditions. If the pressure difference is low and fluid compositions are similar, then production can be taken from a single tubing string. Intelligent well completion also known as smart well completion, which contains inflow control devices and permanent gauges which control the zonal flow and permanent gauges exclude the need of conventional wireline gauges [9].

\section{RESEARCH METHODOLOGY}

Research methodology defines the step by step work on designing the well completion for a multizone well. The initial step was to start based on previous studies. After the literature survey, fluid and reservoir data were collected from the reservoirs of Tal Block. Table I presents PVT data including fluid properties, while Table II presents inflow performance relationship (IPR) related data which define reservoir properties.

TABLE I. PVT DATA

\begin{tabular}{|c|c|}
\hline Parameters & Values \\
\hline Solution GOR (Scf/STB) & 3145 \\
\hline Oil gravity (API) & 39.4 \\
\hline Specific gravity (60/60) & 0.738 \\
\hline Water salinity (ppm) & 1000 \\
\hline $\mathrm{CO}_{2}(\%)$ & 1.5 \\
\hline
\end{tabular}

TABLE II. IPR DATA

\begin{tabular}{|c|c|c|c|}
\hline Parameters & Layer 1 & Layer 3 & Layer 5 \\
\hline Depth (feet) & 12218 & 13940 & 16403 \\
\hline Layer pressure (Psig) & 7417 & 7521 & 7967 \\
\hline Layer flowing radius (ft) & 0.354 & 0.354 & 0.354 \\
\hline Layer GOR (Scf/STB) & 2321 & 3009 & 2067 \\
\hline Layer permeability (md) & 11.7 & 0.94 & 5.55 \\
\hline Skin factor & 42.8 & 36 & 22 \\
\hline
\end{tabular}

It was concluded that Samanasuk formation is a very tight one, having low permeability. So, it was observed that this layer will not flow and the other three layers will be produced. Glaso's correlations were used for calculating gas solubility, formation volume factor, and bubble point pressure of volatile or light oil. Glaso's correlations offer the best accuracy for light oils when compared with other correlations [10].

- Gas solubility:

$$
R_{s}=Y_{g}\left[\left(\frac{\Upsilon_{A P I}^{0.989}}{(T-460)^{0.172}}\right)\left(P b^{*}\right)\right]^{1.2255}
$$

$P b^{*}=10^{x}$

where: $x=2.8869-[14.1811-3.3093 \log (p)]^{0.5}$

- Formation volume factor:

$$
\log \left(B_{o}-1\right)=-6.58511+2.913219 \cdot \log (y)-
$$
$0.27683 \cdot \log (y)^{2}$

where: $y=R_{s}\left(\frac{r_{g}}{r_{o}}\right)^{0.526}+0.968(T-460)$

- Bubble point pressure:

$$
\log \left(P_{b}\right)=1.7669+1.7447 \cdot(x)-0.30218 \cdot \log (x)^{2}(3)
$$

where: $P_{b}=10^{\log (P b)}$ and $x=\left(\frac{R_{s}}{r_{g}}\right)^{0.816} \frac{T^{0.172}}{r_{A P I}^{0.989}}$.

Beggs-Robinson correlation was used to calculate viscosity because of its high accuracy. For volatile oil, Begg's correlation offers less error:

$$
\mu_{o b}=A \mu_{o d}^{B}
$$

where: $A=10.715\left(R_{S}+100\right)^{-0.515}$ and $B=5.44\left(R_{s}+\right.$ $150)^{-0.338}$.

The next step was to generate the IPR curves. The "multilayer-dp loss in wellbore" reservoir model was used to generate the IPR curves for the multizone well. Equation (5) shows the total pressure drops in wellbore in the case of a multilayer well:

$$
\Delta P_{T}=\Delta P_{H H}+\Delta P_{f}
$$

where: $\Delta P_{H H}=\frac{\rho g}{144 g_{c}} h$ and $\Delta P_{f}=\frac{2 f \rho v^{2} L}{144 g_{c} D}$.

$\Delta P_{H H}$ represents hydrostatic pressure losses while $\Delta P_{f}$ represents frictional losses. Begg's and Bill's correlation was used in this case to design the surface equipment, because it is the most accurate correlation to select optimum surface equipment to reduce losses at surface. After that, the vertical lift performance curves were generated based on different variables which showed well performance. Petroleum Experts 2 correlation method was applied to generate vertical lift performance curves. It includes the features of the Petroleum Experts correlation plus original work on predicting low-rate vertical lift performances (VLPs) and well stability. This correlation has been tested for numerous high flow rate cases and found to provide a good estimate of pressure drops.

\section{RESULTS AND DISCUSSION}

The IPR curves were generated with the help of the Prosper software, and show the performance of reservoirs of Tal Block and the production from multizone wells. Well completion was designed and different tubing sizes were selected to check the production. It was concluded that Samanasuk formation was tight and would not flow, so the other three formations are discussed. When an IPR curve meets the VLP curve, the operating point is indicated, which shows that the well will flow. Hence, production rate will be achieved at different tube sizes. Production from multizone wells can be taken from single and dual tubing strings.

\section{A. Case: 1 Single String Multizone Completion}

IPR curves were generated for three producing layers. The reservoir data in Table II were used to calculate IPR curves. Figure 1 shows the three producing layers' IPR curves and the IPR curve of the multilayer well. From the results it is observed that layers 1, 3, and 5 are perforated while intermediate layers are unperforated. Production is possible from only these three layers. Absolute open flow (AOF) shows the maximum production from a well, which is not possible in real conditions, usually a well produces less than AOF. In this case, the AOF from layer 1 is $2936 \mathrm{STB} / \mathrm{D}$, from layer 3 is $179.8 \mathrm{STB} / \mathrm{D}$, and 
from layer 5 is $6905 \mathrm{STB} / \mathrm{D}$. Layer 3 is tight. It has low permeability and high skin value. It is needed to be hydraulic fracturing in future. The overall well IPR is 10021.4 which shows that the well is producing efficiently. Noddle analysis is the combination of IPR and VLP curves while sensitivity analysis is based on different tubing sizes. Figure 2 shows the system performance which is the combination IPR and VLP curves which define the production rate of a single tubing string. The system shows that the production rate from a single string multizone is $5327 \mathrm{STB} / \mathrm{D}$ from a 2.875 inch tube, while using a tubing size of 3.5 inches the production rate is $6702 \mathrm{STB} / \mathrm{D}$. From Noddle analysis it is observed that erosional velocity will be achieved at the earlier stage which will wear the downhole equipment in cases of 2.875" and 3.5" tubes, so mostly 4.5 " and 5.5" tubing sizes are preferred and production rate is $8020 \mathrm{STB} / \mathrm{D}$ and $8697 \mathrm{STB} / \mathrm{D}$ respectively.

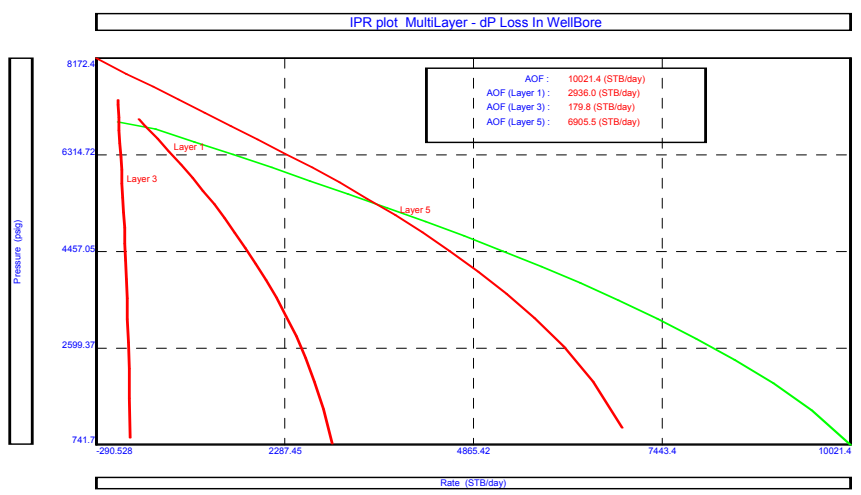

Fig. 1. IPR curves for the three layers and the multilayer well

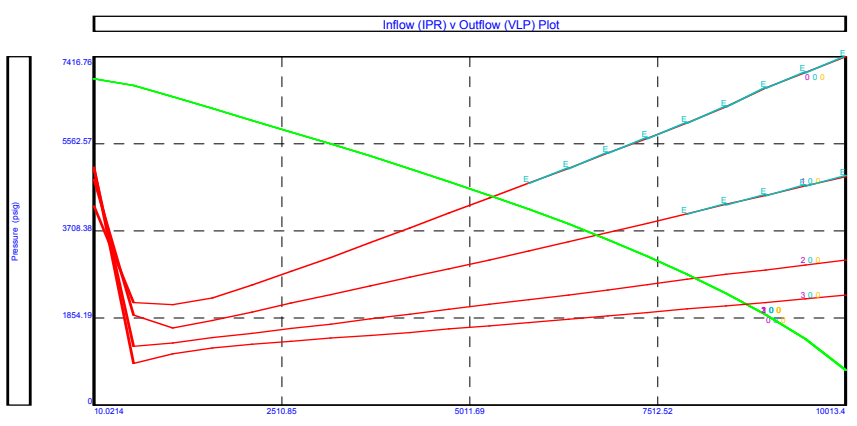

Fig. 2. Flowrates at different tubing sizes for single string multizone

\section{B. Case: 2 Dual String Multizone Completions}

In this case, the well is producing from two tubing strings. Two zones are produced from one string and the rest are produced from the other. In this case, the IPR curve is generated separately for each tubing string production.

\section{1) For Tubing 1}

In this case, the IPR curve is generated for two zones which are produced from one tubing string (Figure 3 ). The AOF from layer 1 is $2936.4 \mathrm{STB} / \mathrm{D}$, while layer 2 is producing $180 \mathrm{STB} / \mathrm{D}$. These two zones commingled show an AOF of 3116.18STB/D. Figure 4 shows two zones producing from one tubing string by utilizing sensitivity analysis. Simulation results show production rates of $2281.9 \mathrm{STB} / \mathrm{D}, 2568.5 \mathrm{STB} / \mathrm{D}, 2777 \mathrm{STB} / \mathrm{D}$ and $2868 \mathrm{STB} / \mathrm{D}$ from tubing sizes of $2.375,2.875,3.5$, and 4.5 inches respectively.

\section{2) For Tubing 2}

The IPR curve in Figure 5 shows the performance of one zone which is the deepest and occupies high pressure. The AOF of zone is $6933.5 \mathrm{STB} / \mathrm{D}$ which shows that it has high reservoir pressure and low skin. Figure 6 shows the deepest zone, which is producing from the other tubing string. The observed production rates are $3416.6 \mathrm{STB} / \mathrm{D}, 4437.6 \mathrm{STB} / \mathrm{D}$, 5283.2STB/D and 5697.5STB/D from tubing sizes of 2.375 , $2.875,3.5$, and 4.5 inches respectively.

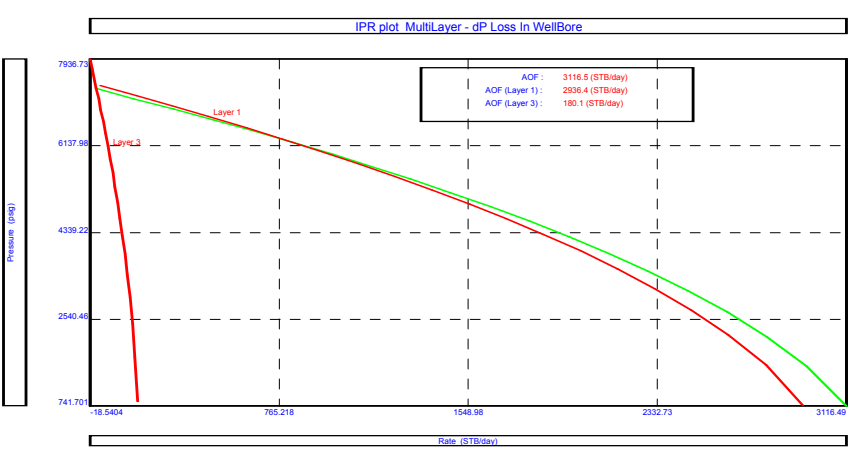

Fig. 3. IPR curves for two zones

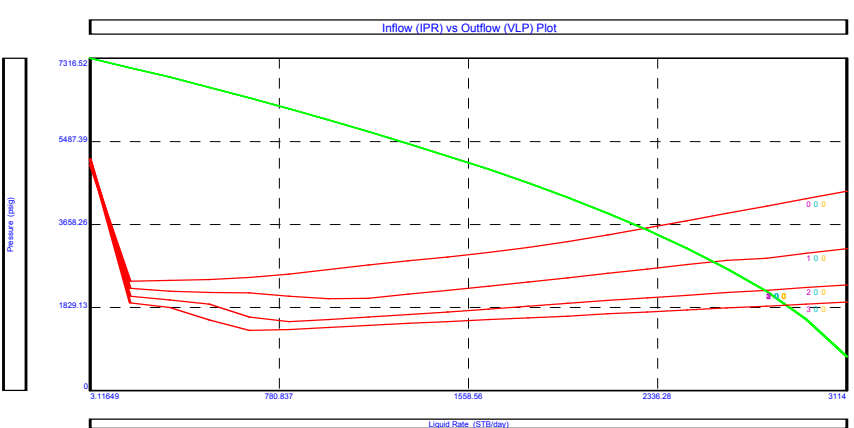

Fig. 4. Flowrates at different tubing sizes for dual string

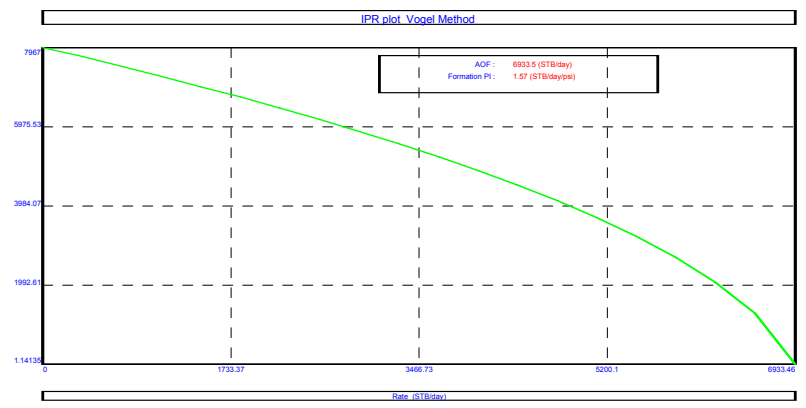

Fig. 5. IPR curve for one zone 


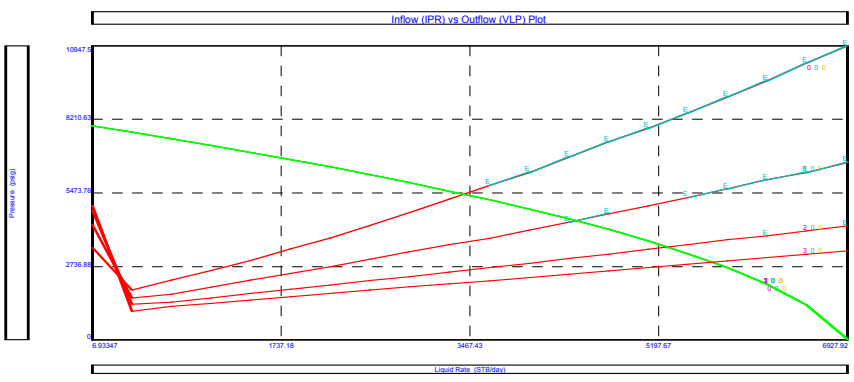

Fig. 6. Flowrates at different tubing sizes for dual string

\section{CONCLUSION}

This study focuses on the comparison of single string multizone completion and dual string multizone completion for a Tal block region well. From the simulation study it is observed that the production from a single tubing string is 8020.2STB/D from a 4.5 inch tubing size, which is quite good production in a cost-effective way. On the other hand, production from a dual string is observed to be $6724.5 \mathrm{STB} / \mathrm{D}$ and $7010.4 \mathrm{STB} / \mathrm{D}$ from tubing size of 2.375 and 2.875 inches respectively. In the case of dual string multizone completion, the production is low from the 2.375 and 2.875 inch tubing size which is not suitable for comparison. It is shown that, in the case of dual string, production is good from two tubing strings of 2.875 inches. Considering a comparison between single tubing string and dual tubing string, the production from the single string is $8020.2 \mathrm{STB} / \mathrm{D}$ from a 4.5 inch tubing size which is quite good when compared to dual string which is 7010.4STB/D. For this multizone well of Tal block region, single string completion is best and most efficient for production.

\section{ACKNOWLEDGEMENT}

Authors wish to thank the Institute of Petroleum and Natural Gas Engineering, Mehran University of Engineering and Technology for providing its facilities.

\section{REFERENCES}

[1] H. Saad, "Barrel along: After a decade, Pakistan resumes crude oil export", The Express Turbine, 2014

[2] H. Saad, "Fifth discovery of oil and gas at Tal block", The Express Turbine, 2010

[3] M. A. Chavez, G. A. Garcia, O. Pogoson, Y. Li, A. H. Cardona, R. N. Nelson, "A Comprehensive Well Completion Design Methodology to Overcome Reservoir Challenges", SPE Annual Technical Conference and Exhibition held in New Orleans, USA, September 30-October 2, 2013

[4] J. Suresh, K. M. Naimi, "Advanced Well Completion Designs to Meet Unique Reservoir and Production Requirements", SPE Saudi Arabia Section Technical Symposium and Exhibition, Al-Khobar, Saudi Arabia, April 21-24, 2014

[5] L. Saputelli, A. Chacon, "Optimum Well Completion Strategies in Tight Oil Reservoirs", Offshore Technology Conference Asia, Kuala Lumpur, Malaysia, March 25-28, 2014

[6] A. Chakraborty, A. B. A. Madzidah, "Well Completion Design Integrity Evaluation Including Thermal and Stress Analysis for Complex Well Completions Offshore", Offshore Technology Conference Asia, Kuala Lumpur, Malaysia, March 22-25, 2016

[7] S. Hamid, R. Jannise, G. Garrison, M. Coffin, "New Technology Provides Zonal Pressure Maintenance in Single Trip Multizone
Completions", SPE Annual Technical Conference and Exhibition, San Antonio, USA, October 9-11, 2017

[8] T. Grigsby, R. Jannise, A. Goodman, B. Techentien, M. Schexnailder, G. Navaira, "The Successful Development and Installation of a New Single-Trip Multizone Completion System Developed for the Deepwater Gulf of Mexico Lower Tertiary Formation", Offshore Technology Conference, Houston, USA, May 2-5, 2016

[9] B. H. Muryanto, W. Fransiskus, R. Wijaya, B. Styward, Y. Ji, E. Albertson, A. W. Sudirgo, A. Hutahaean, A. Widyastuti, "Applications of a Multizone Single-Trip Gravel-Pack System in Developing a Shallow-Gas Field, Indonesia: Case History", Offshore Technology Conference Asia, Kuala Lumpur, Malaysia, March 20-23, 2018

[10] T. Ahmed, Reservoir Engineering Handbook, Gulf Professional Publishing, 2010 